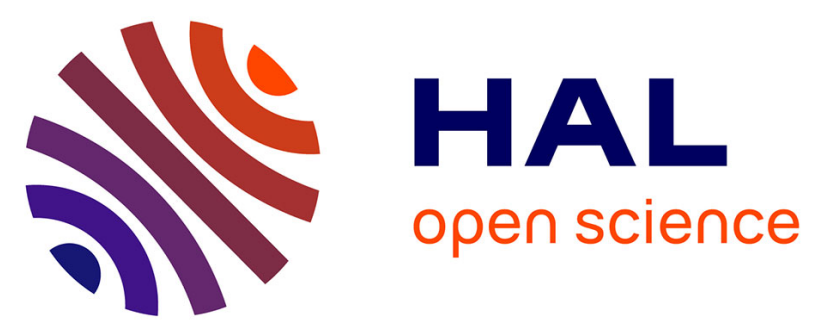

\title{
Analysis of carbohydrates in plants by high-performance anion-exchange chromatography coupled with electrospray mass spectrometry
}

Cédric Guignard, Laurent Jouve, Marie-Béatrice Bogeat-Triboulot, Erwin Dreyer, Jean-François Hausman, Lucien Hoffmann

\section{To cite this version:}

Cédric Guignard, Laurent Jouve, Marie-Béatrice Bogeat-Triboulot, Erwin Dreyer, Jean-François Hausman, et al.. Analysis of carbohydrates in plants by high-performance anion-exchange chromatography coupled with electrospray mass spectrometry. Journal of Chromatography A, 2005, 1085 (1), pp.137142. 10.1016/j.chroma.2005.05.068 . hal-02678625

\section{HAL Id: hal-02678625 \\ https://hal.inrae.fr/hal-02678625}

Submitted on 31 May 2020

HAL is a multi-disciplinary open access archive for the deposit and dissemination of scientific research documents, whether they are published or not. The documents may come from teaching and research institutions in France or abroad, or from public or private research centers.
L'archive ouverte pluridisciplinaire HAL, est destinée au dépôt et à la diffusion de documents scientifiques de niveau recherche, publiés ou non, émanant des établissements d'enseignement et de recherche français ou étrangers, des laboratoires publics ou privés. 


\title{
Analysis of carbohydrates in plants by high-performance anion-exchange chromatography coupled with electrospray mass spectrometry
}

\author{
Cédric Guignard ${ }^{\mathrm{a}, *, 1}$, Laurent Jouve ${ }^{\mathrm{a}, 1}$, Marie Béatrice Bogéat-Triboulot ${ }^{\mathrm{b}}$, Erwin Dreyer ${ }^{\mathrm{b}}$, \\ Jean-François Hausman ${ }^{\text {a }}$, Lucien Hoffmann ${ }^{\text {a }}$ \\ ${ }^{a}$ Public Research Center-Gabriel Lippmann, Environment and Biotechnologies Research Unit, 41 rue du Brill, L-4422 Belvaux, Luxembourg \\ ${ }^{\mathrm{b}}$ UMR INRA UHP Ecologie et Ecophysiologie Forestière, F-54280 Champenoux, France
}

Available online 20 June 2005

\begin{abstract}
A mass spectrometer was coupled to high-performance anion-exchange chromatography (HPAEC) with the help of electrochemical neutralization of the eluent and post-column addition of lithium chloride for carbohydrate analysis. Parallel selective channels (single ion monitoring) were used to decrease the detection limits and separate unresolved peaks. The mass specific detection allowed the simultaneous analysis of a wide range of sugar alcohols, mono-, di- and oligosaccharides. Carbohydrates extracted from leaves of poplar submitted to drought stress were analyzed using pulsed amperometric detection (PAD), then mass spectrometry. It allowed the confirmation of peak attribution and the identification of salicin as a major compound in the extracts. Different responses to water deficit and re-hydration were obtained for several carbohydrates, suggesting different roles in osmoprotection processes.
\end{abstract}

(C) 2005 Elsevier B.V. All rights reserved.

Keywords: Ion chromatography; Anion-exchange; Mass spectrometry; Carbohydrates; Populus euphratica; Salicin

\section{Introduction}

Among the major constituents in plants, carbohydrates are known to vary with season, light availability and vegetative stage, reflecting growth and daily variation of photosynthesis. Carbohydrates are also generally involved in osmoprotection during abiotic stress like hyperosmotic stress. The carbohydrates involved consist in hexoses (mostly fructose and glucose), disaccharides (trehalose, sucrose), sugar alcohols (inositol, mannitol, etc.), and complex carbohydrates (raffinose, stachyose, etc.) [1].

Number of difficulties can be encountered during the chromatographic analysis of carbohydrates, especially due to the high diversity of carbohydrates occurring in nature. In addition, the wide range of functional groups (hydroxyl, amino, acetamino, phosphate) increases the chemical diversity thus greatly complicating the choice of stationary and mobile

\footnotetext{
* Corresponding author. Tel.: +352 470261 850; fax: +352 470264 .

E-mail address: guignard@lippmann.lu (C. Guignard).

1 These authors contributed equally to the paper.
}

phases. Moreover, due to the absence of chromophoric or fluorescent groups, a derivatization step is often required to analyze carbohydrates with conventional detectors. Gas chromatography with FID or MS detection has been employed to separate and identify carbohydrates [2-6]. However, due to their high polarity, hydrophilicity and low volatility, carbohydrates have to be converted into acetate or TMS derivatives before GC analysis. For these reasons, HPLC is often preferred for carbohydrates quantification. Although UV detection can be used [7], underivatized carbohydrates are commonly detected by refractive index detection [8-9]. Recently, a fluorescence detector has been used to detect carbohydrates at the picomole level, after labeling with 2-aminobenzamide [10]. Size-exclusion chromatography, capillary electrophoresis and capillary electrochromatography are less used techniques to analyze carbohydrates [11-14].

High-performance anion-exchange chromatography (HPAEC) coupled with pulsed amperometric detection (PAD) is an efficient method to quantify carbohydrates in natural samples and food products [15-21]. In fact, due to their weak acidic properties $\left(\mathrm{p} K_{\mathrm{a}} \approx 12\right)$, carbohydrates can 
be ionized in strong basic conditions. Thus, an accurate separation of carbohydrates can be achieved by using a strong anion exchange stationary phase and hydroxide solutions as eluent. PAD is an electrochemical method based on the oxidation of carbohydrates on a gold electrode by application of a positive potential. It provides high sensitivity and selectivity, without any time-consuming derivatization step. However, in plant extracts, as in many natural samples, the high complexity of the matrix may lead to coelution and excessive noise. Consequently, interferences between the matrix components and the target compounds can strongly affect the results by hindering peak attribution and integration. The mass spectrometric detection is highly selective and sensitive, and can therefore solve a lot of chromatographic troubles. However, MS is commonly considered to be incompatible with the highly alkaline eluents used in HPAEC. Technical improvements allowing the MS analysis of carbohydrates by HPAEC and results obtained on drought-stressed poplar are described in this work.

\section{Experimental}

\subsection{Samples}

Populus euphratica seedlings were grown for one year under natural daylight in greenhouse conditions, in 51 pots containing a peat/sand mixture $(50 / 50 ; \mathrm{v} / \mathrm{v})$. About $80-100 \mathrm{~cm}$ high plants were then assayed for water deficit tolerance. Imposed drought was applied during 18 days until soil humidity reached $5 \pm 2 \%$ and the plants were then maintained for 10 days under these water deficit conditions before re-hydration. Control plants were irrigated in order to maintain a soil humidity of $23 \pm 3 \%$. P. euphratica leaves were harvested during water deficit conditions at day 18 , after at least 7 days of maintenance at 5\% soil humidity (from Day 25 to 28) and after soil re-watering (Day 32). Generally, four or five different plants were used for leaf sample harvesting, nevertheless only two were used in control conditions at Day 32. Collected samples were directly frozen in liquid nitrogen and stored at $-80^{\circ} \mathrm{C}$ for carbohydrate analyses.

\subsection{Carbohydrates extraction}

About $150 \mathrm{mg}$ of fresh matter were finely crushed in liquid nitrogen and extracted with $1.5 \mathrm{ml}$ of an ethanol/water mixture $(80 / 20 ; \mathrm{v} / \mathrm{v})$ during $1 \mathrm{~h}$. The samples were centrifuged at $3000 \times g$, at $4{ }^{\circ} \mathrm{C}$, during $10 \mathrm{~min}$. The supernatant was recovered and evaporated at reduced pressure. The extract was finally dissolved in $1 \mathrm{ml}$ water, filtered at $0.45 \mu \mathrm{m}$ and analyzed.

\subsection{Analysis of carbohydrates using HPAEC-PAD}

HPAEC-PAD analyses were conducted on a Dionex DX500 chromatograph (Sunnyvale, USA) constituted by a Spark
Midas autosampler, a GP-40 gradient pump and an ED40 electrochemical detector. The analytical column was a Dionex Carbopac PA-10 $(4 \mathrm{~mm} \times 250 \mathrm{~mm})$ with a PA-10 guard column $(4 \mathrm{~mm} \times 50 \mathrm{~mm})$. The eluents were pure water and $300 \mathrm{mM} \mathrm{NaOH}$. Percentages of both eluents were calculated to obtain the desired hydroxide concentration: $12 \mathrm{mM}$ during $25 \mathrm{~min}, 12-150 \mathrm{mM}$ in $1 \mathrm{~min}, 5 \mathrm{~min}$ at $150 \mathrm{mM}$, $150-12 \mathrm{mM}$ in $1 \mathrm{~min}$ and column equilibration at $12 \mathrm{mM}$ during $8 \mathrm{~min}$. The flow rate was $1 \mathrm{ml} \mathrm{min}^{-1}$ and the column was kept at $30^{\circ} \mathrm{C}$. The PAD detection was achieved with a gold working electrode and an $\mathrm{Ag} / \mathrm{AgCl}$ reference electrode, with a data collection rate of $2 \mathrm{~Hz}$. The potential was set to $0.10 \mathrm{~V}$ during $0.41 \mathrm{~s}$ (integration between 0.1 and $0.4 \mathrm{~s}$ ), $-2.0 \mathrm{~V}$ during $20 \mathrm{~ms}, 0.6 \mathrm{~V}$ during $10 \mathrm{~ms}$ and $-0.10 \mathrm{~V}$ during $60 \mathrm{~ms}$. Carbohydrates were quantified using five-points calibration curves, ranging from 1 to $100 \mu \mathrm{moll}^{-1}$.

\subsection{Analysis of carbohydrates using HPAEC-MS}

HPAEC-MS experiments were performed on a Dionex BioLC chromatograph, with an AS-50 autosampler, a GS-50 gradient pump and an EG-50 eluent generator. The mobile phase was on-line generated $\mathrm{KOH}$ at $0.25 \mathrm{ml} \mathrm{min}^{-1}$. The hydroxide concentration was programmed as follows: $10 \mathrm{mM}$ during $22 \mathrm{~min}, 10-100 \mathrm{mM}$ in $1 \mathrm{~min}, 100 \mathrm{mM}$ during $7 \mathrm{~min}$, $100-10 \mathrm{mM}$ in $0.5 \mathrm{~min}$ and column equilibration at $10 \mathrm{mM}$ during $10 \mathrm{~min}$. The analytical column was a Dionex Carbopac PA-20 $(3 \mathrm{~mm} \times 150 \mathrm{~mm})$ with a PA-20 guard column $(3 \mathrm{~mm} \times 50 \mathrm{~mm})$ at $30^{\circ} \mathrm{C}$. The desalter was an ASRS-Ultra with a constant current of $65 \mathrm{~mA}$. The post-column addition of $0.5 \mathrm{mM} \mathrm{LiCl}$ was done with a Dionex AXP-MS auxiliary pump. MS data were acquired on a Finnigan MSQ quadrupole spectrometer with an electrospray interface (ESI). The probe temperature was fixed at $500{ }^{\circ} \mathrm{C}$ with a needle voltage of $3.5 \mathrm{kV}$.

\section{Results and discussion}

\subsection{HPAEC-MS coupling}

Due to their high salinity and low volatility, hydroxide eluents cannot be directly injected through the MS interface, where it can cause electrical shortcuts and capillary plugging by salt crystallization. The usual solution is to dilute alkaline eluents by a post-column addition of water. However, the concentrations of the analytes, and consequently the sensitivity of the detector, are reduced as well with this method. On the contrary, electrochemical desalting, also known as suppression, is an efficient way to convert hydroxide eluents into pure water. The neutralization of $\mathrm{KOH}$ is obtained by a combination of water electrolysis and ion-exchange: $\mathrm{H}^{+}$are produced by the oxidation of water and are then exchanged with $\mathrm{K}^{+}$ions of the eluent, which is therefore neutralized without diluting or modifying the analytes. In these conditions, background noise is significantly decreased 
and the resulting eluent is fully compatible with a MS interface.

Owing to the high polarity and low volatility of carbohydrates, an ESI interface was preferred to atmospheric pressure chemical ionization (APCI). However, as ions are the only detected species in MS, the signal intensity of a molecule is closely related to its ionization yield. For this reason, due to their low ionization yields in ESI or APCI, underivatized carbohydrates are poorly detectable in classical LC-MS conditions. An alternative way to form ions from carbohydrates is to generate adducts with inorganic ions. For that reason, a lithium chloride solution was continuously added before the ESI interface. As a result, the ionization yield and consequently the response factor of carbohydrates were greatly enhanced in positive mode by the formation of $[\mathrm{M}+\mathrm{Li}]^{+}$ions. On the contrary $[\mathrm{M}+\mathrm{Cl}]^{-}$ions were poorly observable in negative mode. An alternative to post-column addition could be a partial suppression of the $\mathrm{KOH}$ eluent, in order to form adducts with the remaining $\mathrm{K}^{+}$ions. However, as the suppressor current must be maintained at a constant value to avoid baseline drifting during analysis, this method cannot be applied with gradient elution.

\subsection{Signal optimization}

The temperature of the capillary and the needle voltage only depend on the flow rate and nature of the eluent. In our case (water-based eluent at $0.25 \mathrm{ml} \mathrm{min}^{-1}$ ), the best results were obtained with $500{ }^{\circ} \mathrm{C}$ and $3.5 \mathrm{kV}$. Conversely, the cone voltage is fully compound-dependant. As expected, low molecular weight carbohydrates require a lower accelerating voltage than heavier carbohydrates. As an example, the optimal cone voltage for pentoses was found to be $70 \mathrm{~V}$ whereas the best results for trisaccharides were obtained with $90 \mathrm{~V}$. In addition to these MS parameters, the post-column addition has to be optimized. On one hand, the concentration of the $\mathrm{LiCl}$ solution has to be sufficient to form adducts with the highest expected amounts of carbohydrates but, on the other hand, an excessive input of $\mathrm{LiCl}$ in $\mathrm{MS}$ can induce a high chemical noise and increases the risk of capillary plugging. As $\mathrm{LiCl}$ concentration, the solution flow rate should not be a limiting factor for adducts formation, but it has to be kept as low as possible to prevent analyte dilution. In our case, the optimal $\mathrm{LiCl}$ concentration and flow rate were found to be $0.5 \mathrm{mmol}^{-1}$ and $0.05 \mathrm{ml} \mathrm{min}^{-1}$, respectively.

\subsection{Efficiency of MS detection}

A large number of parallel selective channels (selected ion monitoring) can be used for critical $\mathrm{m} / \mathrm{z}$, providing an excellent selectivity. Some examples of carbohydrates and corresponding SIM channels are given in Table 1. Most carbohydrates are detected as their $[\mathrm{M}+\mathrm{Li}]^{+}$adduct but, in some cases, the more intense $\left[\mathrm{M}+\mathrm{H}_{2} \mathrm{O}+\mathrm{Li}\right]^{+}$adduct can be used without losing specificity. As illustrated on Fig. 1, coeluting compounds (inositol/pinitol, mannitol/trehalose,
Table 1

Retention factor and detection channel for common carbohydrates

\begin{tabular}{lcl}
\hline Carbohydrate & $k^{\prime}$ & Channel $(\mathrm{amu})^{\mathrm{a}}$ \\
\hline 1. Pinitol & 0.38 & 219 \\
2. Inositol & 0.39 & 187 \\
3. Sorbitol & 0.77 & 189 \\
4. Mannitol & 0.98 & 189 \\
5. Trehalose & 1.04 & 349 \\
6. Arabinose & 4.53 & 175 \\
7. Galactose & 6.04 & 187 \\
8. NAcGlucosamine & 5.99 & 228 \\
9. Glucose & 6.65 & 187 \\
10. Mannose & 7.60 & 187 \\
11. Xylose & 7.71 & 175 \\
12. Sucrose & 7.95 & 349 \\
13. Fructose & 8.91 & 187 \\
14. Lactose & 10.49 & 349 \\
15. Melezitose & 12.72 & 511 \\
16. Melibiose & 12.94 & 349 \\
17. Raffinose & 13.45 & 511 \\
18. 1-Kestose & 15.04 & 511
\end{tabular}

${ }^{\text {a }}$ Adduct used for detection: plain character: $[\mathrm{M}+\mathrm{Li}]^{+}$, italic character: $\left[\mathrm{M}+\mathrm{H}_{2} \mathrm{O}+\mathrm{Li}\right]^{+}$.

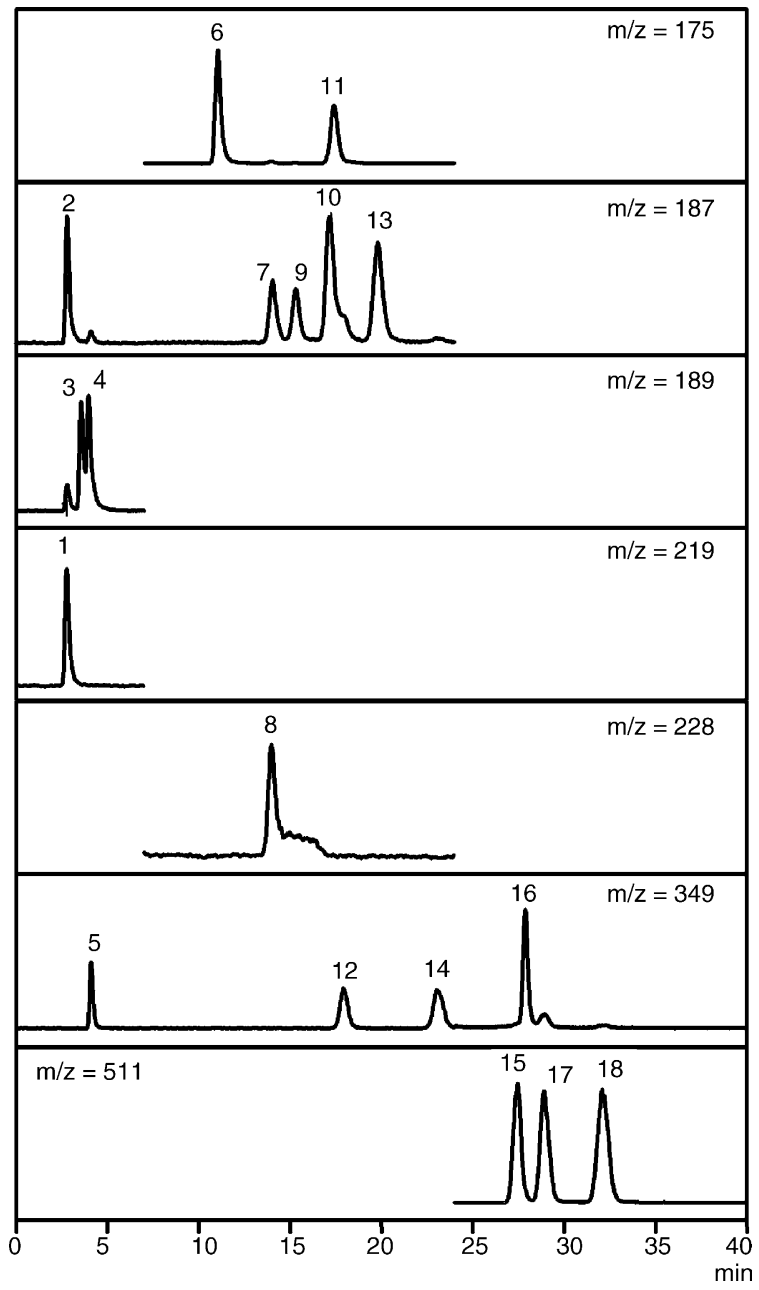

Fig. 1. Simultaneous SIM chromatograms of a standard mixture (18 carbohydrates—see Table 1 for peak numbering). 


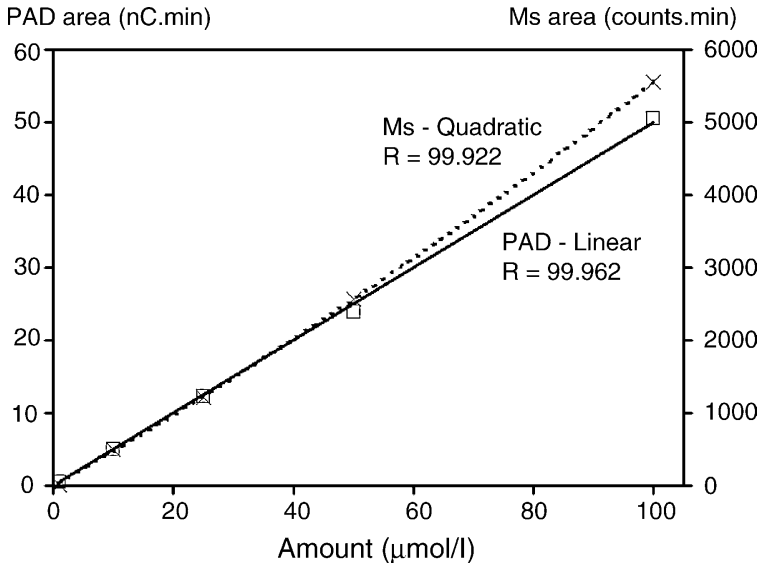

Fig. 2. Calibration curves of glucose in IC-PAD (squares and plain line) and IC-MS (crosses and dotted line).

xylose/mannose, ...) can easily be differentiated by MS detection, which allows the simultaneous analysis of a wide range of carbohydrates, ranging from pentoses and sugar alcohols to di- and trisaccharides.

Extracts from poplar leaves were analyzed using six SIM channels $(0.2 \mathrm{~s}$ dwell time) for selective detection of nine carbohydrates (pinitol, sorbitol, mannitol, trehalose, glucose, fructose, sucrose, raffinose and stachyose) and 1 scan chan- nel (100-1000 uma, $0.5 \mathrm{~s}$ scan time) to investigate unknown compounds. In these conditions, the detection limit was about 5 pmol, which is quite higher than the 1 pmol detection limit obtained with PAD. Nevertheless, the sensitivity of a specific channel can be increased by the attribution of a longer dwell time. In this case, the dwell times of the other channels have to be reduced to maintain the total MS cycle time below a value of $1.5 \mathrm{~s}$, which ensures a correct resolution of chromatographic peaks.

As seen on Fig. 2, the MS detection provides a lower linearity than PAD. This is induced by the exponential MS electromultiplier gain factor. This contributes to consider HPAEC-PAD as the most accurate routine method to quantify carbohydrates, whereas HPAEC-MS provides a better selectivity for problematic samples.

\subsection{Determination of unknown compounds}

A second benefit of MS detection is the availability of mass spectra from unknown peaks. In fact, even if LC/MS spectra are known to provide less information than EI GC/MS spectra, fragmentation of molecules can easily be obtained by increasing the MS cone voltage, as illustrated in Fig. 3. Due to low fragmentation possibilities, fructose mass spectra are quite the same at 100 and $150 \mathrm{~V}$, with three major peaks at $m / z=169,187$ and 205, correspond-
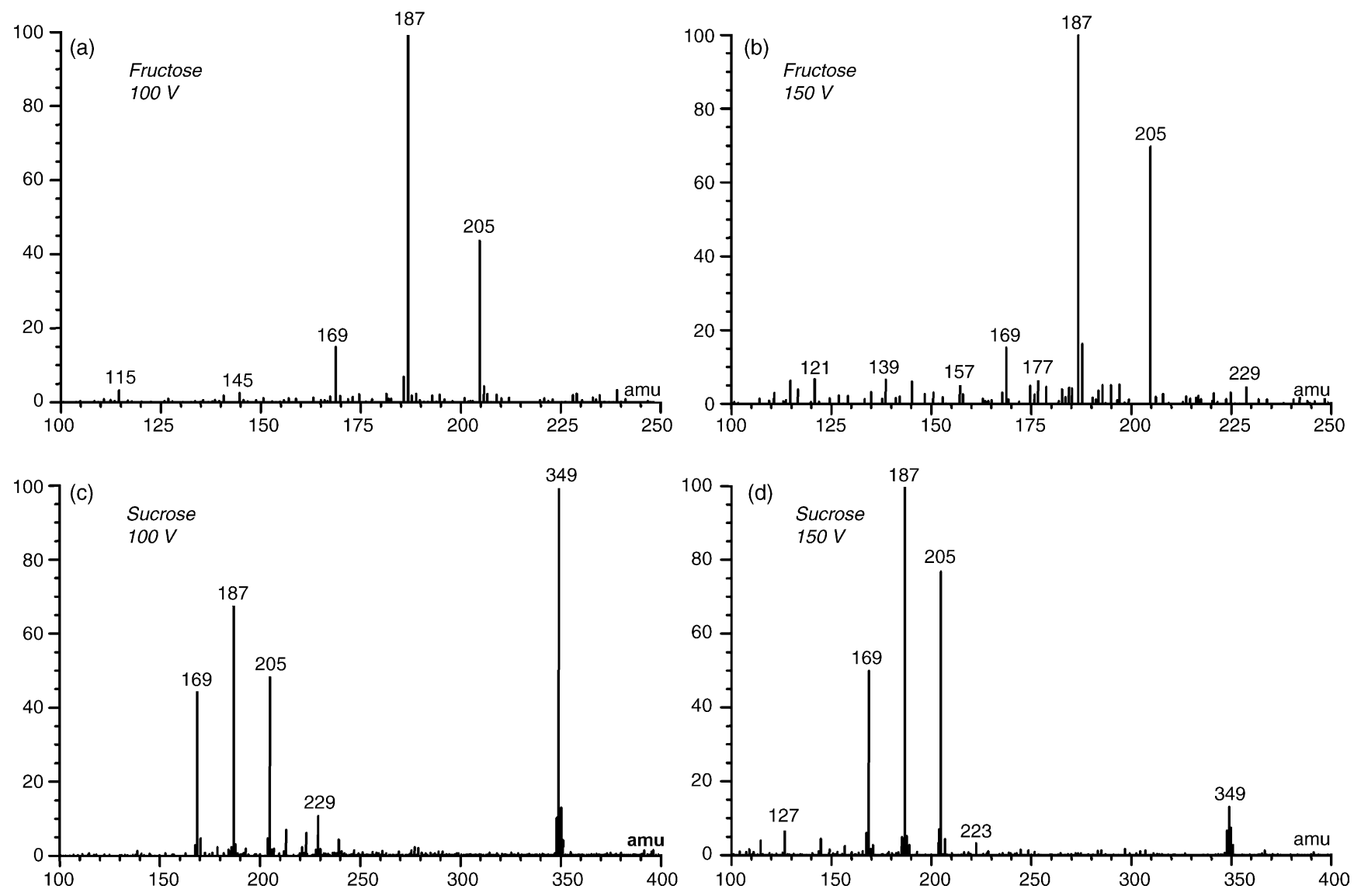

Fig. 3. Mass spectra of fructose and sucrose with 100 and $150 \mathrm{~V}$ cone voltage. 


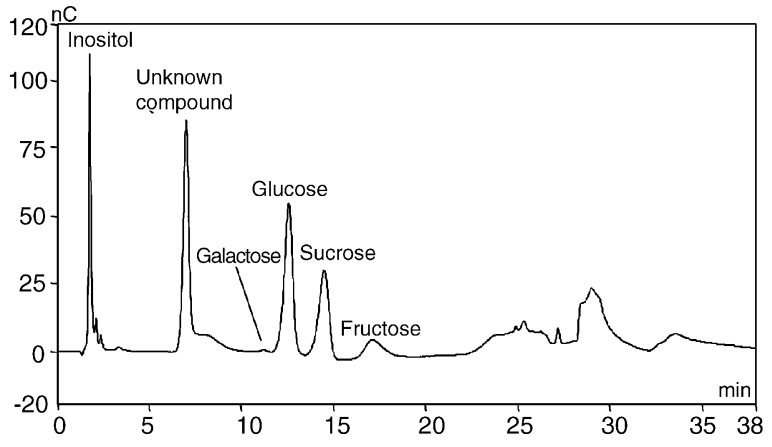

Fig. 4. HPAE-PAD chromatogram of a leaf extract.

ing respectively to $\left[\mathrm{C}_{6} \mathrm{H}_{12} \mathrm{O}_{6}+\mathrm{Li}+\mathrm{H}_{2} \mathrm{O}\right]^{+},\left[\mathrm{C}_{6} \mathrm{H}_{12} \mathrm{O}_{6}+\mathrm{Li}\right]^{+}$ and $\left[\mathrm{C}_{6} \mathrm{H}_{12} \mathrm{O}_{6}+\mathrm{Li}+\mathrm{H}_{2} \mathrm{O}\right]^{+}$ions. The fragmentation of sucrose is significantly different: the pseudo-molecular peak $\left[\mathrm{C}_{12} \mathrm{H}_{22} \mathrm{O}_{11}+\mathrm{Li}\right]^{+}(\mathrm{m} / \mathrm{z}=349)$ is largely prominent at $100 \mathrm{~V}$ whereas glucose and fructose fragments $(\mathrm{m} / \mathrm{z}=169,187$ and 205 ) are enhanced at $150 \mathrm{~V}$.

Fig. 4 shows a typical HPAEC-PAD chromatogram of a poplar leaf extract: in addition to identified carbohydrates, an unknown compound is observed in high amounts. After HPAEC-MS analysis of the same extract, the mass spectrum of this unknown was obtained (Fig. 5a). The pseudomolecular peak $[\mathrm{M}+\mathrm{Li}]^{+}$, occurring at $\mathrm{m} / z=293$ undoubtedly indicated a molecular weight of $286 \mathrm{~g} \mathrm{~mol}^{-1}$. Similarly, the fragments at $m / z=187$ and 169 , characteristic of hexoses, suggested that the structure of the unknown contains a hexose fragment. With the help of the web spectra database [22],
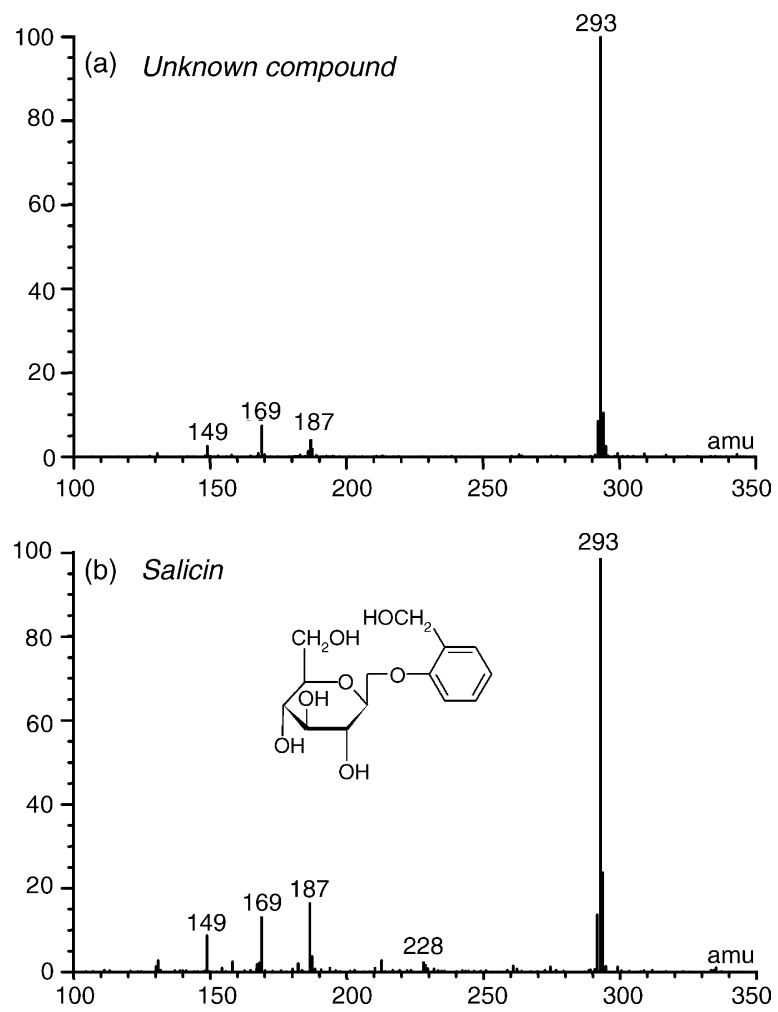

Fig. 5. Mass spectra of unknown compound (a) and pure salicin (b).

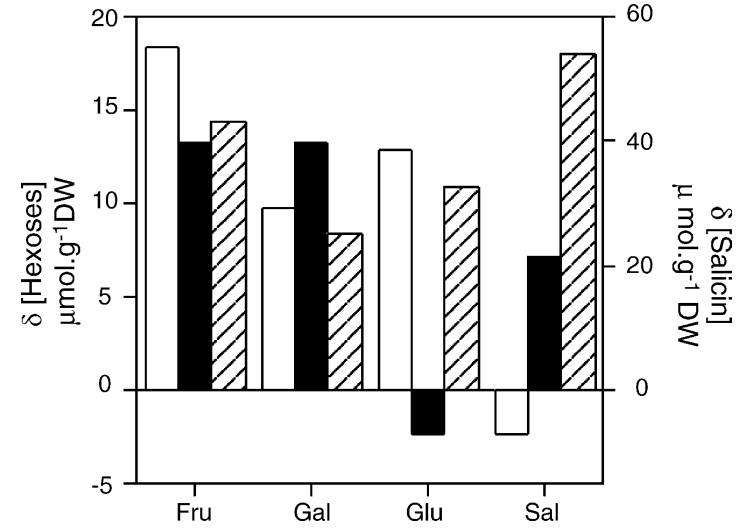

Fig. 6. Variations, normalized to the control, of endogenous fructose (Fru), galactose (Gal), glucose (Glu) and salicin (Sal) levels in leaves of Populus euphratica. Presented data are averages of differences measured between control and stressed plants. White bars: plants after 18 days of drought exposure; black bars: plants from 25 to 28 days of drought exposure; dashed bars: plants 5 days after rewatering after the drought period.

about 80 molecules were found with a MW of $286 \mathrm{~g} \mathrm{~mol}^{-1}$, less than 10 were natural compounds and only five had weak acidic properties. Finally, the only molecule matching with chromatographic and MS results was salicin. By comparison with pure salicin analysis, the structure of the unknown was confirmed by the perfect fitting of retention time and mass spectrum (Fig. 5b).

\subsection{Effect of water stress and rehydration}

Changes in hexoses and salicin endogenous content during water deficit and after re-hydration have been measured. Control plant endogenous content in measured hexoses and salicin did not vary significantly all along the experiment, since statistical tests [23] showed that the probability of rejection of the true null hypothesis was higher than the significant level (i.e. $P>0.05$ ). Galactose level was estimated at $6.5 \pm 2.4 \mu \mathrm{mol} \mathrm{g}^{-1}$ of dry weight, fructose and glucose were quantified at higher levels with respectively $39.2 \pm 8.2$ and $47.7 \pm 8.2 \mu \mathrm{molg}^{-1}$ DW. Salicin was the major carbohydrate in P. euphratica with an average content of $111.7 \pm 26.8 \mu \mathrm{mol} \mathrm{g}^{-1}$ DW. Variations of the carbohydrate levels, normalized to the control, are presented in Fig. 6. Various trends could be observed during the assay: fructose (Fru) and galactose (Gal) contents were higher during drought stress and after re-hydration than in control conditions. This accumulation is probably due to the increase of osmoprotectants needed for drought resistance [24,25]. Furthermore, galactose content decreased after plant watering and plant recovery. Glucose (Glu) accumulated during the first days of the stress and returned to the control level afterwards. Plant watering led to a secondary glucose accumulation. Salicin (Sal) accumulated at the end of the drought treatment, when glucose content returned to a control level. This may indicate that glucose is used, under prolonged water deficit stress, for the synthesis of salicin, thus leading to its accumulation. 
These modulations in compounds taking part in the osmoregulation during drought exposure may reveal adjustment needs for the responses to resist to drought for a long period.

After 28 days of drought, watering led to a decrease in galactose content and an increase in glucose and more severely in salicin. This was already observed in [5] Populus deltoïdes after re-watering following a drought period and could be linked to a need of general osmotic adjustment, including carbohydrates and other molecules as proline, proline analogues, betaine [26] or ions, before the full recovery of the plant.

\section{Conclusion}

A mass spectrometric detector has been coupled with carbohydrate high-performance anion-exchange chromatography, by using electrochemical neutralization of the hydroxide eluent and adduct formation with lithium. A very high specificity was obtained with SIM channels, which allowed the separation of coeluting compounds. A full scan channel was also used to record mass spectra from unknown compounds. Carbohydrates extracted from leaves of water-stressed poplar were analyzed using HPAEC-PAD and HPAEC-MS. The later method permitted to confirm peak attributions and to identify salicin as a major compound in most samples. Contrasted responses of carbohydrates to drought stress were obtained. Fructose and galactose displayed a higher concentration during stress and recovery whereas glucose content displayed a transient increase in drought treated plants but returned to a control level after re-hydration. The endogenous content of salicin increased during water deficit and continued to rise at the end of the drought treatment. On the whole, HPAECMS and HPAEC-PAD have to be considered as complementary techniques: Classical HPAEC-PAD can be routinely used to quantify carbohydrates, whereas HPAEC-MS offers a higher selectivity and is a tool of choice to elucidate unknown peaks.

\section{Acknowledgments}

The authors thank Dr. Frank Höfler and Cees Bruggink, Dionex, for HPAEC-MS technical support. This research was carried out with the financial support from the Commission of the European Communities (contract no. QLK5-CT-200001377), Directorate-General Research-Quality of Life and Management of Living Resources Program.

\section{References}

[1] L. Jouve, L. Hoffmann, J.F. Hausman, Plant Biol. 6 (2004) 74.

[2] F.A. Ayaz, A. Kadioglu, S. Hayirlioglu-Ayaz, Turk. J. Bot. 22 (1998) 65.

[3] W. Morelle, G. Strecker, Biochem. J. 330 (1998) 469.

[4] P. Abreu, A. Relva, Carbohydr. Res. 337 (2002) 1663.

[5] G.M. Gebre, J.R. Brandle, M.R. Kuhns, Tree Physiol. 17 (1997) 341.

[6] S. Lein, M. VanBoven, R. Holser, E. Decuypere, G. Flo, S. Lievens, M. Cokelaere, J. Chromatogr. A 977 (2002) 257.

[7] B.P. Naidu, Aust. J. Plant Physiol. 25 (1998) 793.

[8] A. Savadogo, C.A.T. Ouattara, P.W. Savadogo, N. Barro, A.S. Ouattara, A.S. Traoré, Afr. J. Biotechnol. 3 (2004) 189.

[9] D. Del Pozo-Insfran, D. Urias-Lugo, C. Hernandez-Brenes, S.O. Serna Saldivar, J. Inst. Brew. 110 (2004) 124.

[10] D.R. Wing, B. Garner, V. Hunnam, G. Reinkensmeier, U. Andersson, D.J. Harvey, R.A. Dwek, F.M. Platt, T.D. Butters, Anal. Biochem. 298 (2001) 207.

[11] S. Hokputsaa, C. Hub, B.S. Paulsenc, S.E. Harding, Carbohydr. Polym. 54 (2003) 27.

[12] S. Suzuki, S. Honda, Chromatography 22 (2001) 171.

[13] W. Guo, J.A. Koropchak, C. Yan, J. Chromatogr. A 849 (1999) 587.

[14] C. Martinez Montero, M.C. Rodriguez Dodero, D.A. Guillen Sanchez, C.G. Barroso, Chromatographia 59 (2004) 15.

[15] C.J.M. Stroop, C.A. Bush, R.L. Marple, W.R. LaCourse, Anal. Biochem. 303 (2002) 176.

[16] T. Masuda, K. Kitahara, Y. Aikawa, S. Arai, Anal. Sci. 17 (2001) 895.

[17] M.W. Davis, J. Wood Chem. Technol. 18 (1998) 235.

[18] M. Schiller, H. von der Heydt, F. März, P.C. Schmodt, J. Chromatogr. A 968 (2002) 101.

[19] Y.C. Lee, J. Chromatogr. A 720 (1996) 137.

[20] X. Cheng, L.A. Kaplan, J. Chromatogr. Sci. 41 (2003) 1.

[21] C. Bunte, M. Simon, Limnol. Oceanogr. 44 (1999) 1862.

[22] http://www.aist.go.jp/RIODB/SDBS/menu-e.html.

[23] R.R, Sokal, F.J, Rohlf, Biometry the Principles and Practice of Statistics in Biological Research, W. H. Freeman, New York, p. 887.

[24] P.S. Low, R. Gilles, M. Gilles-Baillien (Eds.), Transport Processes, Iono- and Osmoregulation, Springer-Verlag, Berlin, 1985, p. 469.

[25] R.G. Wyn Jones, R. Storey, R.A. Leigh, N. Ahmad, A. Pollard, E. Marre, O. Cifferi (Eds.), Regulation of Cell Membrane Activities in Plants, Elsevier, Amsterdam, 1977, p. 121.

[26] B.P. Naidu, L.G. Paleg, G.B. Jones, Aust. J. Biol. 48 (2000) 611. 